\title{
A Research on the Application of Constructivism to Martial Art Teaching in Colleges and Universities
}

\author{
Zhenfei Cui, Yu Guo \\ Xi'an University of Technology, Xi'an City, Shaanxi Province, 710048, \\ China
}

\begin{abstract}
Constructivism teaching model is a student-centered teaching model. Teachers play the role of organizer, instructor, helper and facilitator in the whole teaching process and they make use of learning environment of scene, collaboration and conversation to give full play to students' initiative and enthusiasm. The ultimate goal is to enable students to effectively achieve the meaning construction of current knowledge. Based on the author's learning and practical experience, this article first examines the traditional martial art teaching and then analyzes the influence of constructivist learning theory on martial art teaching. Finally, the author puts forward martial art teaching methods based on the constructivist theory.

Keywords: Constructivism; Colleges and universities; Martial art teaching; Influence; Teaching method
\end{abstract}

\section{Introduction}

Constructivist learning theory is advocated by an American scholar, Jeffrey Schulman,. He believes that learners are the center of learning, the main body of information processing and the active constructor of meaning. The process of learning is a process that in the context of certain social and cultural background, students use the necessary learning materials and take the initiative to construct new knowledge based on their existing knowledge and experience with the help of others. This learning process has the characteristics of initiative, society and situation. It takes the student as the center and the teacher as the organizer, the 
helper, the guider and the facilitator in the whole teaching process. By making use of the real learning environment elements of scene, collaboration, dialogue and meaning construction, teachers can stimulate students' enthusiasm and initiative to enable students to effectively construct the knowledge ultimately. The reason why we advocate the reconstruction of the martial art teaching model with the students as the main body, which is based on the constructivist learning theory, is that martial art combines the ancient Chinese philosophy, ethics, religion, strategics, medicine, art and so on[1]. With a variety of functions and values, such as fitness, self-defense, entertainment, appreciation, and communication, martial art are rich in variety, variety of sports equipment, sports routines and action lines. Those distinctive features are in line with the setting of ideal teaching situations advocated by constructivist learning theory, such as situation design, attempting collaboration, conversational communication and meaning construction. Therefore, constructivist learning theory not only has theoretical guidance on the reconstruction of martial art teaching model, but also has a strong practical operation value.

\section{A survey on the traditional martial art teaching}

Modern scientific theory has been the basis of physical education theory. The traditional martial art teaching is an important part of the physical education teaching. The traditional teaching idea is based on the behavioral learning theory with teaching knowledge as its characteristics and students' imitation as the main means of learning. On the basis of cognitive learning theory, students are placed in the dominant position in teaching, while teachers play a leading role, and control and adjust the learning process by reasonably simplifying and reforming teaching materials. These two kinds of teaching theories have always been dominant in martial art teaching activities in China and they are characteristics of teaching activities. The former is teacher-centered; teachers tell students the correct methods and answers, and the students imitate and practice; teachers make evaluation according to the students' performance. The latter is a learning theory supported by computer technology, which can explain the inner structure and process of students' learning more accurately. These two kinds of teaching theories have neglected other factors that influence students 'learning, such as the motive, the influence between teachers and students, the learning environment and the role of social and cultural background. This lead to separation between students' learning environment and social reality. With the rapid development of modern information science and technology, it provides a technical basis for the study and application of constructivist learning theory. The constructivist learning theory has been widely applied to various teaching practice. It also changes and influences martial art teaching ideas, teaching content and methods. 


\section{The Influence of Constructivist Learning Theory on Martial Art Teaching}

Teachers are the spreaders of knowledge. They regard students as products with unified specifications and develop a unified teaching objective in each class. Teachers impart knowledge with these objectives and the learning styles are totally decided by teachers. Although students have learned a certain amount of technical skilled movement knowledge in the traditional martial art teaching, the practical thinking and creative thinking cannot gain long-term development without application of the actual knowledge. It is not beneficial for the students to assimilate and adapt the new knowledge they have learned to the actual situation and students do not have the chance to give the new knowledge a certain meaning, so that the original experience cannot assimilate the new knowledge.

Constructivist learning theory is no longer rigidly limited to imparting knowledge of martial art, where the important thing is the cultivation of quality and students' ability development. In the course of teaching, students can actively form knowledge and construct new knowledge by mastering the main points and laws with owing space to cultivate positive thinking, discover and solve problems and form knowledge autonomous thinking .

As a means of education, martial art is one of the most important teaching materials of all kinds of school physical education curriculum. Nowadays, the simple martial art knowledge can not meet the needs of current society. Modern teaching theories, especially the constructivist learning theory, can fully tap the cultural value and significance of martial art movement to human education and development. This cultural value and significance goes deep into the spiritual level and have a positive impact on human body, mind, behavior, which benefit people for life.

In the course of martial art teaching, there exists flow of knowledge and information between teachers and students. With the pursuit of the speed, quality and interaction of the flow, we can optimize the teaching process. Constructivist learning theory establishes an equal cooperative relationship between teachers and students in teaching. The role of teachers change their role from the knowledge authority to the sources of knowledge for students and from the knowledge transmitter to students' learning facilitator. This reflects the equality between teachers and students with love as the link, which strengthen learning activities[2].

Learning environment refers to the atmosphere and environment formed in the process of learning, which is an important factor in martial art teaching. Modern teaching theory emphasizes the formation of a good learning situation. Collective learning atmosphere, the cohesion between students and good teacher-student relationship constitute a micro-social environment in martial art teaching activities. Martial art is a project with high-degree unity between the collective and individual, which is different from other competitive sports. It requires a high demand of the learning situation. Therefore, in the classroom learning, we should actively build learning situation factors. The cooperative learning model based on constructivist learning theory is an effective way to optimize the learning 
situation. Martial art has high innovation, practical nature, performing feature and traditional characteristics. Inheritance, innovation and development are the embodiment of its strong vitality[3].

The interactive learning model guided by the constructivist learning theory requires teachers and students to communicate, inspire and complement with each other. In the process of teaching, teachers and students' thoughts crash and mingle with each other. They share their thinking, emotion and experience to enrich learning means and find new things in order to achieve and common development of teaching and learning.

\section{Martial Art Teaching Methods Based on Constructivism}

\subsection{To create learning situation and carry out "training during learning"}

Constructivism requires students to acquire knowledge through active learning. Teachers should encourage students to use a variety of sensory organs in martial art teaching. "Hand, eye, body, method and step; mind, spirit, movement and power" are basic elements of martial art. Students should practice in learning to understand martial art routines, motor skills and martial art knowledge in the formation process. They not only know the results, but also witness the process. In a sense, the process is more important than the results, because the martial art movement itself is the process of development of knowledge. Students construct knowledge in the process and reproduce knowledge in the future through the process of memory. For example, When students learn martial art attack and defense, and its offensive and defensive implications, they will be associated with the learning situation and knowledge some years later when watching a game.

Martial art teaching should strengthen the intuitive teaching and exploration activities to practice in learning. Martial art intuitive teaching includes the use of human models, board, slide, pictures, martial art teaching films and electronic computers, except the demonstration. Intuitive teaching is no longer just guided by the teacher and students participate in the process independently[5]. The use of intuitive methods of learning is not to verify knowledge but to discover knowledge and to establish the corresponding knowledge and experience.

Martial art teaching should also go out of the classroom to carry out practical inquiry activities in the living environment, including to watch the game, to participate in a variety of martial art groups and gymnastics activities, to apply their knowledge, technology and martial art knowledge, to practice and to join in martial art cultural background social survey and statistical analysis. This will help develop students' practical thinking. Students learn things in practice. They no longer memorize technical actions and routines mechanically, but get real and useful knowledge of martial art through their own understanding of construction. They can use the learned knowledge to solve problems in new situation to promote their physical and mental development. 


\subsection{To broaden the learning background and use case teaching}

Martial art is a unique traditional sports in China, which has been developing for thousands of years. According to historical records, Japanese karate is evolved from Wuzu Boxing. There exist various forms of martial art activities everywhere in people's lives. Students have accumulated a lot of martial art knowledge background in this living environment and a variety of media. The extensive use of local martial materials is one of the basic principles of teaching. In the teaching of martial art, it is helpful to construct the knowledge of martial art and understand the content of martial art by connecting their living environment and martial art experiences. It is in favor of assimilating the knowledge of martial art. Of course, students' experience and background is always limited, which requires teachers to provide students with some examples as learning background to implement example teaching. Case teaching is also known as anchored teaching and problem-based teaching, which refers to that the teacher creates a real event or a real problem situation in the teaching process. By using case teaching, students' cognitive model in the initial state can not assimilate new information and produce cognitive imbalance. This will improve students' cognition level through comprehensive analysis of cases, revising or reconstructing new schemata to achieve new balance. At the same time, students have different understanding of the same case, which may cause controversy. This help to develop creative thinking. Taking the case into their own experience in the system, this will help to develop practical thinking. The reform and development of martial art movement has provided us with a large number of practical background and factual material, which gives us good conditions for using case teaching method. For example, the current media held a variety contests of Tai $\mathrm{Chi}$ and $\mathrm{Wu} \mathrm{Zu}$ Boxing, which are good examples. In the use of examples, teachers should focus on effectiveness, heuristic, pertinence and representativeness[4].

\subsection{To encourage cooperative learning in martial art teaching}

Constructivists advocate to establish learning groups to carry out cooperative learning to correct errors in students' learning. The mistakes in learning are meaningful. When the error occurs and is corrected in time, the discussion of the study group is meaningful. Research shows that if one wants to convey the content of his own experience and meaning to others, first, he should generalize and classify the content and this process is the product of thinking. In martial art teaching, we should establish learning groups with 4-6 people in each to carry out cooperative learning. In the classroom, the learning group members can discuss the learning objectives, learning methods and other issues, so that each student can become active participant in learning activities. For example, students analyze different characteristics, operation skills and routines of Tai Chi and Changquan. Students learn with problems and by asking questions. Then, they discuss problems and take active thinking and critical thinking to develop their 
own ideas and theoretical explanations, so as to form a shared and active learning construction.

\subsection{To enrich the evaluation of martial art with the constructivist evaluation system and improve the learning evaluation methods}

Constructivism believes that learning is the construction of a meaningful explanation and the learning process is a mirror of knowledge construction. Therefore, constructivist teaching evaluation is based on dynamic, continuous and persistent learning process, the progress of learners, teaching strategy and the learning environment adopted by teachers. We cannot view the results statically and we should pay attention to the evaluation of the learning process of each learner, because each student has different basis, origins and intelligence[6]. As long as there is progress and their own ideas, we should praise them. Only using the constructivist evaluation system to enrich the connotation of martial art teaching evaluation, can we construct an objective, comprehensive and fair evaluation system to design the teaching according to the learners' needs, and to improve and optimize the teaching strategies. This will make the knowledge construction process more effective and optimized.

\section{Conclusion}

The specific teaching subject of martial art has been affected by the modern teaching theories in the teaching principles, teaching structure, teaching methods and teaching contents. Therefore, using constructivist learning theory to guide and explore the martial art teaching problems has a positive significance. Martial art teaching reform should discard bad things in the traditional martial art teaching and use the constructivist theory to update the teaching concept. It is necessary to adopt the constructivism-based teaching strategies and constructivist martial art teaching model. It follows that how to use constructivism to guide the reform of martial art teaching still needs further study.

\section{Acknowledgements}

Scientific research project in Xi'an University of technology: Item No. 602211402.

\section{References}

[1] Song Yi. A Research on the Implications of Constructive Learning Theory to the Reconstruction of Martial Art Teaching Model in Colleges and Universities. Journal of Jilin Institute of Physical Education,01, pp.120-121, 2008.

[2] Yuan Xiaojun. A Study on the Influence of Constructivist Learning Theory on Martial art Teaching. Journal of Chifeng University (Natural Science Edition), 05, pp.57-60, 2008. 
[3] Zhou Weibo, Huang Xiaohua. An Analysis of the Use of Constructivism in Martial Art Teaching. Journal of Hubei Adult Education Institute, 04, pp.139$140,2012$.

[4] Tuo Wanliang. A Discussion on the Constructivist Teaching View and Martial Art Teaching Reform . Boxing (Martial Art Science) ,08, pp.59-60, 2012.

[5] OUYANG Xinhui, Chen Jianshu. A Study on the Application of Constructivism in Martial Art Teaching in Colleges and Universities . Sports World (Academic Edition), 07, pp.21-23, 2007.

[6] Xiong Shanying. Martial Art Teaching from the Perspective of Constructivist model . Journal of Hunan Mass Media Vocational and Technical College ,05, pp.112-113, 2006. 